\title{
The global emergence of severe acute respiratory syndrome coronavirus 2 in human
}

\author{
Bikash Mandal ${ }^{1}$
}

Published online: 26 June 2020

(C) Indian Virological Society 2020

\begin{abstract}
Coronaviruses are spherical and enveloped RNA viruses that infect diverse vertebrates like mammals, birds and fish. There are five human coronavirus species and all of their origin is linked to animal like bat and rodent. The two coronavirus species, Middle East respiratory syndrome-related coronavirus and Severe acute respiratory syndrome-related coronavirus are lethal to human. In the second week of December 2019, there was an outbreak of pneumonia of unknown cause in the people associated with a seafood market in Wuhan, China. The disease was designated as coronavirus disease 2019 (COVID-19) and the virus was identified as severe acute respiratory syndrome coronavirus 2 (SARS-CoV-2) of the genus Betacoronavirus. SARS-CoV-2 being highly transmissible and pathogenic, soon it has spread to 213 countries killing $>0.47$ million people. The information on the research findings of SARS-CoC-2 are pouring from all over the world. In a special issue of VirusDisease, "The global emergence of coronavirus in human", various topics relating to emergence, potential cases, transmission dynamics, diagnosis, pathogenesis, food safety, therapeutic strategies and antiviral properties of Ayurveda products are covered.
\end{abstract}

Bikash Mandal

leafcurl@ rediffmail.com

1 Division of Plant Pathology, Advanced Centre for Plant Virology, Indian Agricultural Research Institute, New Delhi 110012, India

\section{Introduction}

Viruses have extraordinary host specificity and generally remain within the boundary of a kingdom of living species and based on this feature, viruses are known by their broad host range like animal virus, bacterial virus, human virus, plant virus etc. The genetic material of the viruses is small and is highly prone to rapid changes during their parasitic life process. The changes in the nucleotide sequence alter their mode of persistence in the living host cells. In a rare instance, the changes are so appropriate that enable a virus to overcome the species barrier and jump from one kingdom to another. The interkingdom host switching is known in case of circovirus infecting vertebrates like bird, chimpanzee, dog, fish, human and pig. The molecular evidence shows that the circovirus has originated from a plant virus, nanovirus [7]. It appears that switching host of nanovirus to animal and then recombination with a RNA virus, (calicivirus) in animal resulted in emergence of circovirus in animal. After switching to a novel host, virus adapts through mutation and or recombination for successful proliferation within and between the cells as well as for successful subsequent transmission to healthy individuals of the same species. This sequence of events results in to origin, evolution and emergence of new viruses [10]. There are past instances of interspecies transmission of virus from animal to human that resulted in outbreak of zoonotic viral diseases in human eg., human immunodeficiency virus from chimpanzees [12], H1N1 type influenza A virus from birds (Spanish flu) [14], Nipah virus from fruit bat/pig [2] and measles virus from cattle [6]. Coronavirus from bat or other intermediate animals is the latest episode of zoonotic disease that soon turned pandemic. At present, the fear of coronavirus looms everywhere in the world resulting locked down in human society. 


\section{Coronaviruses}

Coronavirus is a spherical enveloped RNA virus. The genome is relatively large containing a copy of positive sense single-stranded RNA of $27-32 \mathrm{~kb}$. The virion membrane contains virus encoded spike protein, the major antigenic determinant that facilitates receptor attachment and fusion leading to the entry to the host cell [16]. Coronaviruses infect diverse vertebrates like mammals, birds and fish. They are classified under the subfamily Orthocoronavirinae of the family Coronaviridae. The subfamily Coronavirinae has four genera, Alphacoronavirus, Betacoronavirus, Gammacoronavirus and Deltacoronavirus. The alphacoronaviruses and betacoronaviruses infect mammals. The genus Alphacoronavirus contains 19 species of which only two are human coronavirus species: Human coronavirus 229E, Human coronavirus NL63. The genus Betacoronavirus contains 14 species of which three are human coronavirus species: Human coronavirus HKU1, Middle East respiratory syndrome-related coronavirus and Severe acute respiratory syndrome-related coronavirus. Not all human coronaviruses are severe pathogens, the respiratory syndromerelated coronaviruses are only lethal to human, whereas, the others are generally mild pathogens.

\section{The outbreak}

In the second week of December 2019, a serious public health threat surfaced in the city of Wuhan, China. The major disease symptoms were of pneumonia with fever and respiratory distress. The cause of the disease was unknown; however, it was linked to a local wholesale wet market in Wuhan [9]. Between December 2019 and January 2020 about 75,000 people were affected by the disease in Wuhan [11]. The World Health Organization (WHO) declared this event as a public health emergency of international concern on the 30 January 2020. The name of the new disease was announced by WHO as coronavirus disease-2019 (COVID19) on 11 February 2020 . The disease was highly transmissible and soon it had spread to other countries. WHO, on 11 March 2020 declared COVID-19 as a pandemic disease. By 23 June 2020, it had spread to 213 countries and territories infecting 9,193,156 people including 4,74467 deaths.

Currently, coronavirus is shaking the world. Coronavirus outbreak in human is not new, during the last 2 decades, there were two more episodes of epidemic. The first epidemic of coronavirus causing severe acute respiratory syndrome (SARS) broke out during November 2003 in Guangdong province, China [4]. Soon, the virus associated with the SARS was identified as SARS coronavirus (SARS-CoV) [18]. SARS-CoV had spread to 29 countries and territories killing about 774 people. The major epidemic lasted for 8 months and by 18 May 2004, WHO announced the end of the epidemic (https://www. who.int/csr/don/2004_05_18a/en/). The second epidemic of respiratory syndrome caused by coronavirus emerged during 2012 in Saudi Arabia [1]. Subsequently, the major disease outbreak occurred in the Middle East countries, however it has been reported from as many as 27 countries. The virus associated with the disease was identified as Middle East respiratory syndrome coronavirus (MERS$\mathrm{CoV})$ of the species Middle East respiratory syndromerelated coronavirus under genus Betacoronavirus. MERS$\mathrm{CoV}$, which was shown to be transmitted from dromedary camels to human, continues to spread as the update of WHO showed a total of 2519 confirmed cases of MERS globally at the end of January 2020.

\section{The virus identity}

Soon after the outbreak of the pneumonia in Wuhan, studies ruled out the association of commonly known respiratory pathogens. In the Wuhan Institute of Virology, by the first week of January, 2020, a coronavirus was isolated from the samples of the patients of the initial outbreak of the disease, who were sellers or deliverymen from the seafood market [19]. Five out of seven samples in the initial RT-PCR test with the pan-coronavirus primers showed positive amplification. In order to identify the specific virus, one positive sample (WIV04) was subjected for the metagenomics analysis using next-generation sequencing and finally a genome of 29,891 nucleotides was obtained, which shared $79.6 \%$ sequence identity with SARS-CoV BJ01 [19].

\section{Naming new disease}

For a new viral disease, there are three names to be designated, the disease, the virus and the virus species. WHO named the disease as COVID-19, The International Committee on Taxonomy of Viruses (ICTV) designated the virus associated with COVID-19 as severe acute respiratory syndrome coronavirus 2 (SARS-CoV-2) and the virus species as Severe acute respiratory syndrome-related coronavirus [8]. 


\section{The mutation and diversity}

Since the outbreak of SARS-CoV-2 in China, numerous genome sequence data of the virus have been generated. A study with 7666 public genomic data sets identified 198 recurrent mutations in the SARS-CoV-2 genome [3]. Majority of the mutation is located in Orflab encoding Nsp6, Nsp11, Nsp13, and spike protein. The mutation rate of SARS-CoV-2 is approximately $10^{-6}$ nucleotides per site per cell, which is similar to SARS-CoV or other RNA viruses [13].

The spike (S) protein, which is projected outward on the surface of the virion is the very important pathogenic determinant. The S protein has two subunits, S1 and S2. The S1 binds on angiotensin-converting enzyme 2 (ACE2), the host cell receptor, and the S2 mediates membrane fusion. The receptor-binding domain (RBD) of S1 binds ACE2. The Cryo-electron microscopic structure of the spike protein of SARS-CoV-2 has been determined at $3.5^{\circ} \mathrm{A}[15]$. The study showed SARS-CoV-2 S protein has higher affinity to ACE2 compared to that of SARS-CoV. The mutation at 614 position in the $\mathrm{S}$ protein of SARSCoV-2 from aspartic acid to glycine (D614G) was identified to reduce S1 shedding and increases infectivity [17]. The sequence analysis showed that the G614 genotype has steadily increased from March to May 2020, indicating a transmission advantage of the virus with G614 mutation [17].

The diversity analysis of SARS-CoV-2 with 160 complete genome sequence showed three central variants referred as A, B, and C. The variant-A is the ancestral type. The $\mathrm{A}$ and $\mathrm{C}$ types are found in Europeans and Americans. The B type is predominant in East Asia [5].

\section{The special issue of VirusDisease}

SARS-CoV-2 has created the wide spread fear of death. As the virus has newly emerged, there is no known drug or vacine, however, with all possible available knowledge and tools concerted efforts are being made to protect people from SARS-CoV-2. In order to develop effective and new treatment options, researchers are racing with their investigations and findings are exploding from all over the world. The search of full text journal articles of coronavirus during the last six months showed $>9000$ documents in PubMed, which is an indicator of such a great effort of the scientific community at the time of tragedy. VirusDisease, an international journal is publishing articles on all aspect of virus disease research. During April 2020, we planned a special issue of VirusDisease on "The global emergence of coronavirus in human" and very soon numerous articles were submitted to the journal indicating a great interest and concern about the topic. The special issue of VirusDisease presents 20 articles including the article types of review, commentary, original article and short communication covering the subject areas on emergence of the disease, potential cases, transmission dynamics, diagnosis, pathogenesis, food safety and hygiene, therapeutic strategies and antiviral properties of Ayurveda products.

\section{References}

1. Al-Osail AM, Al-Wazzah MJ. The history and epidemiology of middle east respiratory syndrome corona virus. Multidiscip Respir Med. 2017;12:20. https://doi.org/10.1186/s40248-0170101-8.

2. Chua KB, Bellini WJ, Rota PA, Harcourt BH, Tamin A, Lam SK, Ksiazek TG, Rollin PE, Zaki SR, Shieh W, Goldsmith CS, Gubler DJ, Roehrig JT, Eaton B, Gould AR, Olson J, Field H, Daniels P, Ling AE, Peters CJ, Anderson LJ, Mahy BW. Nipah virus: a recently emergent deadly paramyxovirus. Science. 2000;288(5470):1432-5.

3. Dorp LV, Acman M, Richard D, Shaw LP, Ford CE, Ormond L, Owen CJ, Pang J, Tan CCS, Boshier FAT, Ortiz AT, Balloux F. Emergence of genomic diversity and recurrent mutations in SARS-CoV-2. Infect Genet Evol. 2020. https://doi.org/10.1016/j. meegid.2020.104351.

4. Feng D, Sake DV, Li-Qun F, Xiao-Na H, Wen-Juan Z, Sheng S, Hong Y, Zhong-Wei J, Hendrik RJ, Wu-Chun C. The SARS epidemic in mainland China: bringing together all epidemiological data. Trop Med Int Health. 2009;14(s1):4-13. https://doi.org/ 10.1111/j.1365-3156.2008.02145.x.

5. Forster P, Forster L, Renfrew C, Forster M. Phylogenetic network analysis of SARS-CoV-2 genomes. PNAS. 2020;117(17):9241-3. https://doi.org/10.1073/pnas.2004999117.

6. Furuse Y, Suzuki A, Oshitani H. Origin of measles virus: divergence from rinderpest virus between the 11th and 12th centuries. Virol J. 2010;7:52. https://doi.org/10.1186/1743-422X7-52.

7. Gibbs MJ, Weiller GF. Evidence that a plant virus switched hosts to infect a vertebrate and then recombined with a vertebrateinfecting virus. PNAS. 1999;96(14):8022-7.

8. Gorbalenya AE, Baker SC, Baric RS, et al. The species Severe acute respiratory syndrome-related coronavirus: classifying 2019-nCoV and naming it SARS-CoV-2. Nat Microbiol. 2020;5:536-44. https://doi.org/10.1038/s41564-020-0695-z.

9. Hui DS, Azhar E, Madani TA, Ntoumi F, Kock R, Dar O, Ippolito G, Mchugh TD, Memish ZA, Drosten C, Zumla A, Petersen E. The continuing 2019-nCoV epidemic threat of novel coronaviruses to global health-the latest 2019 novel coronavirus outbreak in Wuhan. China. Int J Infect Dis. 2020;91:264e6.

10. Longdon B, Brockhurst MA, Russell CA, Welch JJ, Jiggins FM. The evolution and genetics of virus host shifts. PLoS Pathog. 2014;10(11):e1004395. https://doi.org/10.1371/journal.ppat. 1004395 .

11. Poon LLM, Peiris M. Emergence of a novel human coronavirus threatening human health. Nat Med. 2020;26:317-9. https://doi. org/10.1038/s41591-020-0796-5.

12. Sharp PM, Hahn BH. The evolution of HIV-1 and the origin of AIDS. Philos Trans R Soc Lond B Biol Sci. 2010;365(1552):2487-94. 
13. Shen Z, Xiao Y, Kang L, Ma W, Shi L, Zhang L, Zhou Z, Yang Y, Zhong J, Yang D, Guo L, Zhang G, Li H, Xu Y, Chen M, Gao Z, Wang J, Ren L, Li M. Genomic diversity of SARS-CoV-2 in coronavirus disease 2019 patients. Clin Infect Dis. 2020. https:// doi.org/10.1093/cid/ciaa203.

14. Webby RJ, Webster RG. Emergence of influenza A viruses. Philos Trans R Soc Lond B Biol Sci. 2001;356(1416):1817-28.

15. Wrapp D, Wang N, Corbett KS, Goldsmith JA, Hsieh CL. CryoEM structure of the 2019-nCoV spike in the prefusion conformation. Science. 2020;367:1260-3. https://doi.org/10.1126/sci ence.abb2507.

16. Wu C, Liu Y, Yang Y, Zhang $\mathrm{P}$, Zhong W, Wang Y, et al. Analysis of therapeutic targets for SARS-CoV-2 and discovery of potential drugs by computational methods. Acta Pharm Sin B. 2020. https://doi.org/10.1016/j.apsb.2020.02.008.
17. Zhang L, Jackson CB, Mou H, Ojha A, Rangarajan ES, Izard T, Farzan M, Choe H. The D614G mutation in the SARS-CoV-2 spike protein reduces S1 shedding and increases infectivity. 2020. https://doi.org/10.1101/2020.06.12.148726.

18. Zhong NS, Zheng BJ, Li YM, Poon XZH, Chan KH, Li PH, Tan SY, Chang Q, Xie JP, Liu XQ, Xu J, Li DX, Yuen KY, Peiris GY. Epidemiology and cause of severe acute respiratory syndrome (SARS) in Guangdong, People's Republic of China, in February, 2003. Lancet. 2003;362:1353-8.

19. Zhou P, Yang X, Wang X, et al. A pneumonia outbreak associated with a new coronavirus of probable bat origin. Nature. 2020;579:270-3. https://doi.org/10.1038/s41586-020-2012-7.

Publisher's Note Springer Nature remains neutral with regard to jurisdictional claims in published maps and institutional affiliations. 